\title{
Simón, Cristina (2020). Cartapacios de consulta sobre variación dialectal hispánica. Plano lingüístico: fonética, morfosintaxis y léxico. CEPE, UNAM.
}

Erika Ehnis Duhne

Centro de Enseñanza para Extranjeros Universidad Nacional Autónoma de México

En esta época ha habido grandes avances en muchas áreas del conocimiento, impulsados especialmente por el desarrollo de las tecnologías; sin embargo, se siguen presentando rezagos en la investigación de algunos campos de la lingüística. Es de sobra conocida la necesidad apremiante que hay de obras que analicen y reflexionen acerca de la lengua española, especialmente acerca de las variantes hispanoamericanas. Recordemos lo que al respecto señala Lara (2013:17), quien explica cuál fue su punto de partida en la minuciosa investigación que realizó para escribir acerca del desarrollo del español en sus múltiples ubicaciones:

\begin{abstract}
Me parece no sólo una necesidad, sino una obligación, tratar la historia del español en todos los territorios en que se habla; lamentablemente, o los estudios particulares sobre la historia del español en la mayor parte de los países hispanoamericanos son todavía demasiado exiguos y fragmentarios, o no los encontré en nuestras bibliotecas, por lo que, a pesar de esa necesidad, no he podido tratar el español de esas regiones como debiera ser [...].
\end{abstract}

La Organización de las Naciones Unidas para la Educación, la Ciencia y la Cultura (Unesco, 2005), analiza la relevancia del manejo de los usos adecuados de la terminología en las comunidades de hablantes en todo el planeta -en referencia a la desventaja que tienen las lenguas minoritarias frente a las mayoritarias-. A este respecto, Pozzi (2016: 42-43) afirma que “...la terminología constituye la base de la comunicación especializada y es fundamental para proporcionar a las comunidades en desarrollo acceso a la información, esto es, a los contenidos, y por ende, acceso al conocimiento... [el cual] debe ser transferido en una lengua que pueda ser entendida por toda la comunidad". Por su parte, Colín (2016) señala que "la investigación sobre los procesos cognitivos de comprensión de textos en México es escasa [...]; aun cuando a la fecha han surgido nuevos trabajos en el área, observamos que este vacío no ha sido atendido".

Tres puntos de vista diferentes han sido señalados aquí, como muestras breves de la gran necesidad de investigación lingüística que aún hay sobre la lengua 
española, y en especial, sobre las realizaciones del español de Hispanoamérica. Por eso es de gran valía la publicación de Cartapacios de consulta sobre variación dialectal hispánica, pues viene a llenar un vacío de información con gran profesionalismo. Este manual esclarece, a la vez que organiza, los dialectos del sistema de la lengua española, que sin esta herramienta es posible localizar, pero con mucha dificultad, o de manera dispersa, incompleta y confusa. Comprobamos al leerlo la escrupulosidad que guió a la autora en su larga investigación, hasta lograr la presentación clara del contenido. Este breve manual contiene tanto una exposición sencilla de los tópicos más relevantes de la lingüística, como una sólida argumentación en temas polémicos. Véanse, por ejemplo, las notas al pie de las páginas 13 y 59.

Tanto por la compleja temática del libro -dialectología-, como por la metodología con que fue creado, este manual debe ser catalogado como fuera de serie, y por ello, puede muy bien identificarse con la frase: el libro es "chiquito, pero picoso". Con este dicho de gastronomía mexicana hacemos alusión al hecho de que, a pesar de tener una extensión breve (se aprecia un "chile chiquito" de solo 109 páginas), sus temas se abordan con amplitud (es un "chile muy potente, picoso": explica muchos hechos de la lengua).

Simón Ruiz inicia el manual señalando dos aspectos: a) la valiosa unidad de la lengua española- español panhispánico-, sin importar la zona geográfica en el mundo donde se realice, y b) ningún dialecto de la lengua española puede considerarse como incorrecto, no importa de qué variante se trate. La autora demuestra ser especialista en estos temas, en los que ha profundizado durante su larga experiencia enseñando a alumnos mexicanos y extranjeros. Igual que la lengua española, la autora experimentó en su propia vida ese "trasplante" de Europa a América.

Simón Ruiz aclara el objetivo del manual en las primeras páginas: ser una guía de toda la variación geolectal diatópica hispánica contemporánea, que abarca España e Hispanoamérica. Los niveles de lengua en los que la autora decidió dividir su análisis son el fonético, morfosintáctico y léxico ${ }^{1}$. La creación de este libro resulta sui generis por el equilibrio entre fond o y forma: la variación lingüística tan compleja del español de Hispanoamérica - que incluye 22 países

Aunque la descripción chomskiana de la competencia lingüística se lleva a cabo en cuatro niveles: fonológico, morfológico, sintáctico y semántico, en este libro se cumple ampliamente el objetivo de Cristina Simón, que es en otro nivel (llevar a cabo la descripción dialectológica con obvio sentido práctico), gracias a la manera en que fusionó planos y explicó sus objetos de estudio. 
actualmente (Pozzi, 2016: 44), y su estructura de manual didáctico: cualquier tema queda al alcance de una búsqueda sencilla de realizar en sus páginas.

La autora aborda su análisis desde dos frentes. En uno de ellos expone la actitud hegemónica del español peninsular en el papel político mundial y de qué manera interactúa con las otras naciones del planeta, adoptando el papel de un árbitro ante los países de habla castellana. En el otro frente analiza usos puntuales de los hablantes, que recurren a las variantes en el momento de la emisión de su mensaje comunicativo dentro de su comunidad. Tres ejemplos que encontramos en el manual son los siguientes: a) los usos de vos (como segunda persona pronominal de singular -en registro informal-), respecto a los cuales la autora señala: "El voseo ha sufrido diferente suerte en su devenir en Hispanoamérica, no es uniforme ni siquiera en los países netamente voseantes" (Simón: 70); b) el leísmo, que se refiere al uso del pronombre personal de objeto indirecto, en vez del directo: "Vi a Pedro: le vi, en vez de lo vi" (Simón: 76); c) los diminutivos en México y otros países de Hispanoamérica, (donde se usa más ito) y en partes de España, Cuba, República Dominicana, Venezuela, Colombia, Costa Rica (donde se usa más -ico) (88-91).

Al inicio del manual, Simón Ruiz aclara que esta obra es una guía dirigida a profesores de español como lengua adicional (ELA, usualmente denominada como Español Lengua Extranjera, ELE), a estudiantes para profesores de ELE y a estudiantes extranjeros que aprenden español. Podríamos añadir aquí a traductores ${ }^{2}$, profesores y estudiantes de lenguas extranjeras (porque al aprender "la otra lengua" es cuando afloran más dudas de la propia), y al público en general. Son innumerables las dudas que le surgen al hablante común y que este libro podrá aclararles, como, por ejemplo, ¿coser (con aguja e hilo) o cocer (en cazuela hirviendo)? por cambio ortográfico, lo que se complica oralmente debido al seseo/ciseo/zezeo/ceceo (36-39); ¿verdad o berdá? por neutralización de la labiodental y bilabial (32) y con pérdida de la dental al final de palabra (44); ¿español o castellano? (17 y 19), ¿españolismo o americanismo? (99 y 101), ¿México o Méjico?3. A lo largo de esta obra se encuentran inventariados y analizados estos y muchos otros elementos. Asimismo, en las explicaciones utiliza su denominación especializada, es decir, no se refiere a la lengua general, sino a los términos lingüísticos específicos (e. g. hiato, antistecón, epéntesis, leísmo de cortesía, reduplicación de posesivos, préstamos híbridos,

2 Acerca del tema de variación lingüística y traductología, se puede consultar Franco (2020) sobre cómo traducir un cuento de Rulfo.

3 Este uso de la grafía equis sigue siendo polémico en el registro escrito del español peninsular (Méjico - con la grafía jota-) y el del español mexicano (México - con la grafía equis-). Véase la p. 54 del libro, donde la autora se refiere a un texto de Alfonso Reyes relacionado con este tema. 
africanismos), por lo que este manual suma otro gran aporte al área: es un tesoro terminológico.

Las referencias bibliográficas son un valioso cimiento de este manual. Por un lado, se incluyen obras clásicas en el campo, como, por ejemplo, las de Lapesa, Kany, Quilis, RAE, Bello, Lope Blanch, Moreno de Alba, Lara, Company, $y$, con especial atención, de Antonio Alatorre. La autora también señala sitios virtuales indispensables, tales como el de la Universidad de lowa ${ }^{4}$. Por otro lado, la cuidadosa selección de la bibliografía al final de cada capítulo le proporciona al lector autonomía para convertirse en su propio instructor.

Hacemos la sugerencia de que se publique esta obra también de manera virtual, para su mayor alcance y difusión, además de editarla en forma de glosario con ejemplos (en apps), o al menos, con un índice de contenidos. Las partes que nos parecen más valiosas son el análisis fonético -el contraste dialectal es muy completo-, y la exposición de corpus y diccionarios.

La postura de Cristina Simón Ruiz es erudita y crítica. Es un libro de cabecera obligado no solo para los estudiosos de la lengua española, sino para toda la población que desee conocer mejor su propio idioma.

\section{REFERENCIAS}

Colin, Marisela (2016). Terminología: necesidad de planificación en México. Avances en lexicografía, terminología y traducción. Marisela Colín y Erika Ehnis (coords.). Centro de Enseñanza de Lenguas Extranjeras, unam, 161.

Franco, E. (2020). Reflexiones en torno a la variación léxica en el ámbito hispánico y la traducción. ELA, 38, (71) https://ela.enallt.unam.mx/index.php/ ela/article/view/905

Lara, Luis Fernando (2013). Historia mínima de la lengua española. El Colegio de México, El Colegio Nacional.

Pozzi, María (2016). Terminología: necesidad de planificación en México. Avances en lexicografía, terminología y traducción. Marisela Colín y Erika Ehnis (coords.). Centro de Enseñanza de Lenguas Extranjeras, unam, 42-43. UNESCO (2005). Guidelines for terminology policies: formulating and implementing terminology policy in language communities. Organización de las Naciones Unidas. $\quad$ http://www.termnet.org/downloads/english/projects/IFAP/14_ termtrain2005_sauberer_guidelines_ci2005.pdf

4 Sitios de libre acceso como este son un referente para profesores, estudiantes y especialistas, al poner al alcance recursos como su simulador del aparato fonador, los artículos especializados, etcétera. 